\title{
Design and Implimentation of a Microcontroller Based Digital Thermometer
}

\author{
${ }^{1}$ I. G. Saidu, ${ }^{1}$ M. Momoh, ${ }^{4}$ H. N. Yahaya, ${ }^{1}$ D. O. Akpootu, ${ }^{2}$ I. Z. Yaroko, \\ ${ }^{3}$ S. A. Fagbemi and ${ }^{2}$ A.A. Sifawa \\ ${ }^{l}$ Department of Physics, Usmanu Danfodiyo University, Sokoto, Nigeria. \\ ${ }^{2}$ Department of Physics, State University, Sokoto, Nigeria. \\ ${ }^{3}$ M. Sc. Student, Department of Physics, Usmanu Danfodiyo University, Sokoto, Nigeria. \\ ${ }^{4}$ Sokoto Energy Research Centre, Sokoto, Nigeria.
}

\begin{abstract}
In the field of healthcare, temperature monitoring has assumed a very vital role both in the management of patient's condition and general hospital storage facilities. Current advancements in the technology of temperature measurement have led to a huge variety of sensors and measuring instruments now being available for making accurate measurements. Most of the types available locally are the analogue type. In this work, a digital thermometer has been designed and constructed based on ATMegal6 microcontroller using LM35 as the temperature sensing device. The design is in four modules; power supply, temperature sensor, $L C D$ device and ATmegal6 modules. While the ATmegal6 forms the main control element, the temperature sensor senses the temperature to be measured and converts it to a corresponding analogue voltage. The measured temperature is displayed on a 16 by 2 Character LCD incorporated in the system. The system was tested and the results showed a mean deviation of $\pm 0.5^{\circ} \mathrm{C}$ from the readings when compared to a standard digital thermometer (ST-9269 MULTI-STEM THERMOMETER) reading. The thermometer is most suitable at higher temperatures.
\end{abstract}

Keywords: Design, microcontroller, thermometer, LCD, Temperature.

\section{Introduction}

The name thermometer is coined from the Greek words thermo meaning "warm" and meter, "to measure" (Wikipedia, 2011). Thermometers measure temperature, by using materials that change in some way when they are heated or cooled (Bellis, 2011).

The invention and creation of the first working thermometer has been credited variously to Abu Ali Ibn Sina, Cornelius Drebbel, Robert Fludd, Galileo Galilei andSantorioSantorio (Helden, 1995; Sigurssen, 2003; Wikipedia, 2011). Modern thermometers are calibrated in standard temperature units such as Fahrenheit or Celsius and Kelvin. A thermometer has two important elements: the temperature sensor in which some physical change occurs with temperature, plus some means of converting this physical change into a numerical value (Wikipedia, 2011). The temperature precision or resolution of a thermometer is simply to what fraction of a degree it is possible to make a reading.

In this paper a digital thermometer was designed and constructed using AVR microcontroller device. The block diagram for the thermometer is as shown in fig 1.The design is in four modules; power supply, temperature sensor, LCD device and ATmega16 modules. While the ATmega16 forms the main control element, the temperature sensor senses the temperature to be measured and converts it to a corresponding analogue voltage. The digital value of the measured temperature is then displayed on an LCD device. The power supply section provides the required voltages for the other three sections.

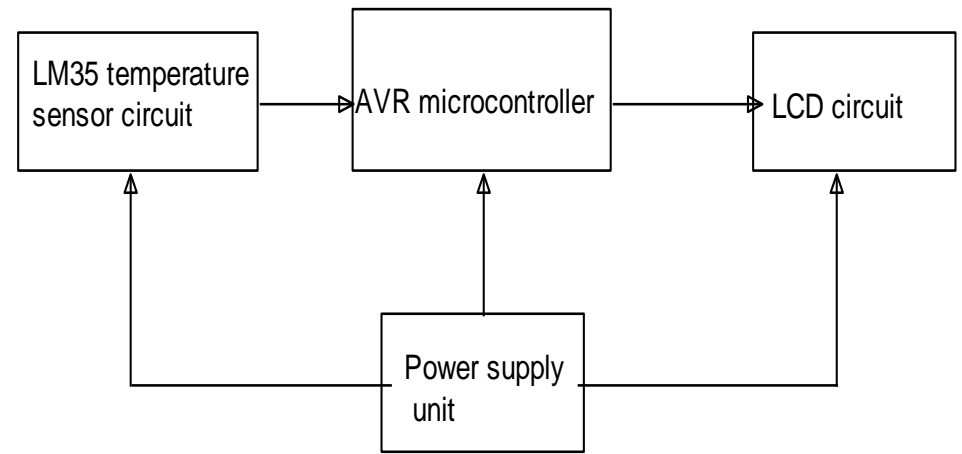

Figure 1: block diagram of the digital thermometer 


\section{Power Supply}

\section{Design}

The power supply requirements for the three sections of the project are all 5V (LM35 Data sheet, 2006; ATmega16 Data sheet, 2007; LCD data sheet, 2000). An LM7805 voltage regulator was used to provide steady $5 \mathrm{~V}$ supply for the three sections. For the voltage regulator to regulate properly provision must be made for drop out voltage. For this reason the input voltage to the regulator is specified (LM7805 Data sheet, 2011).

$7 \mathrm{~V} \leq \mathrm{Vin} \geq 20 \mathrm{~V}$

A $9 \mathrm{~V}$ battery was used as the input voltage to the regulator.

The supply connections to the various sections is shown in Figure 2

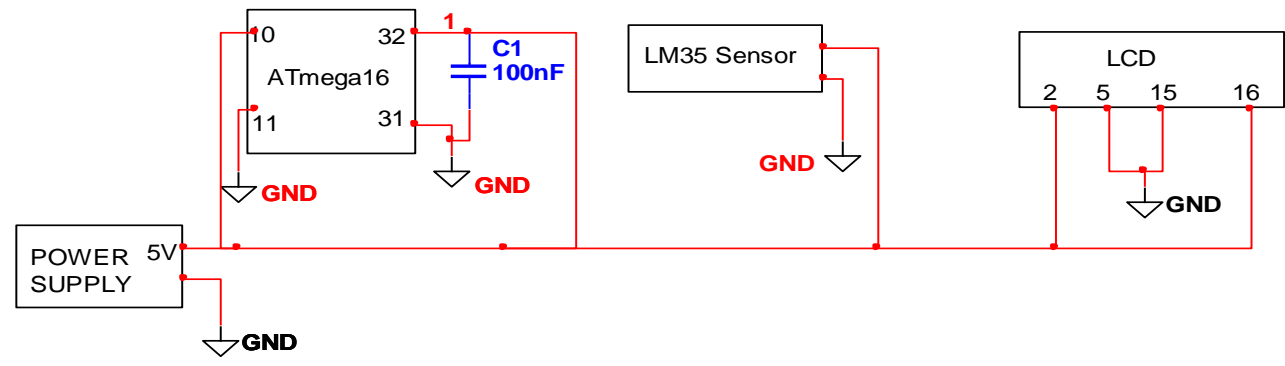

Figure 2: The supply to the various sections

\section{Lm35 temperature sensor circuit}

The fundamental necessity of the research is the conversion of the measured temperature into a corresponding electrical signal. There are many transducers capable of performing this, among which are thermocouple, thermistor and LM35 IC series. For convenience, availability and many inherent advantages a version of the LM35 series is chosen for this project.

The LM35 series are precision integrated-circuit temperature sensors, whose output voltages are linearly proportional to the Celsius (Centigrade) temperature. The LM35 thus has an advantage over other temperature sensors calibrated in Kelvin, as the user is not required to subtract a large constant voltage from its output to obtain convenient Centigrade scaling. The LM35 does not require any external calibration or trimming and has low output impedance, linear output, and precise inherent calibration that make interfacing to readout or control circuitry especially easy. As it draws only $60 \mu \mathrm{A}$ from its supply, it has very low self-heating (LM35 Data book, 2010).

One common temperature sensor in the LM35 series available in the market is LM35DZ. There are other temperature sensing components in the same series like LM334, DS1820 etc. This project has made use of the LM35DZ; this is because of its availability and the range of temperature it can handle. The LM35DZ is a precision semiconductor temperature sensor giving an output of $10 \mathrm{mV}$ per degree Centigrade rise.

According to its data sheet (LM35 Data book, 2010) an RC circuit should be connected across the output and ground of the LM35DZ, if a long cable is used. This is to reduce the capacitive effect of the cable. A capacitor of $1 \mathrm{uF}$ and a resistor of $100 \mathrm{ohms}$ were connected across the IC as shown in figure 3

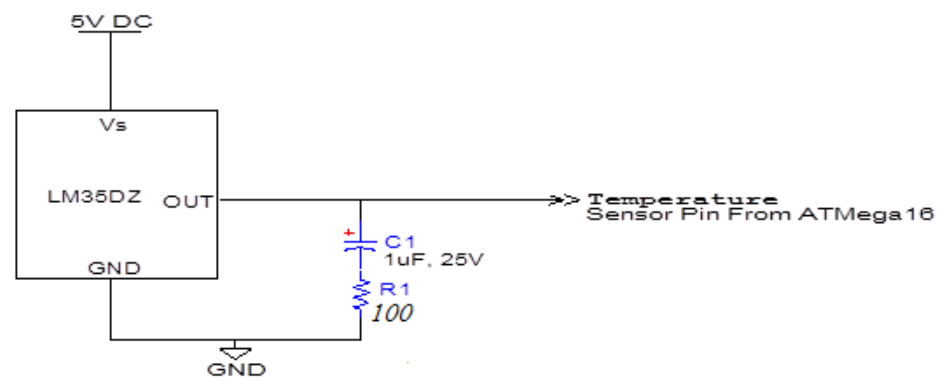

Figure 3: LM35 sensor circuit

\section{LCD circuit}

The LCD employed is a $16 \times 2$ type capable of displaying 32 characters in alphanumeric form. It has a wide range of LCD driver power from -3 to $1 \mathrm{~V}$ with high speed MPU bus interface of $2 \mathrm{MHZ}$ when the supply voltage is $\mathrm{V}_{\mathrm{cc}}=5 \mathrm{~V}$. It can also be configured as 4 bit or $8-$ bit interface enabled to transmit or receive data in either 4 bits or 8 bits. It consumes very small power with automatic reset circuit that initializes the controller/driver after power on. Internally there is an oscillator that has external resistors (LCD Data book). 
The LCD was configured to drive its dot-matrix under the control of 4- bit output of the microcontroller.

A regulated supply of $5 \mathrm{~V}$ was used to supply the chip which is within the recommended supply voltage of the chip. A $100 \Omega$ resistor was included as a current limiting resistor. The pin 16 of the chip is the $\mathrm{V}_{\mathrm{cc}}$ while pin 1 is the ground and was connected to the 0 line of the supply. Since only four bits are used to receive data from the micro, the upper nibble of the byte line was used while the lower nibble (Do to $D_{3}$ ) was connected to the ground as recommended in the data sheet. To achieve this, pins 7, 8, 9 and 10 (upper nibble) were grounded while pins 11 to pin 14 (lower nibble) were connected to receive the 4-bit data from the main micro. A variable resistor is provided to adjust the brilliance of the LCD. The value as recommended in the datasheet is from 10k to 30k. For this project, a 10k variable resistor was used to vary the brightness of the LCD. Pin 5 of the LCD is used as the enable pin to activate the device and set it for operation. Pin 4 is the reset pin that is used to clear the registers of the LCD. The data transfer from the microcontroller is completed after the 4 bit data has been transferred twice. The order of transfer is that the four lower order bits $\left(D_{4}\right.$ to $\left.D_{7}\right)$ are transferred before the four higher order bits $\left(\mathrm{D}_{\mathrm{o}}\right.$ to $\left.\mathrm{D}_{3}\right)$.

The circuit configuration of the LCD circuit is as shown.

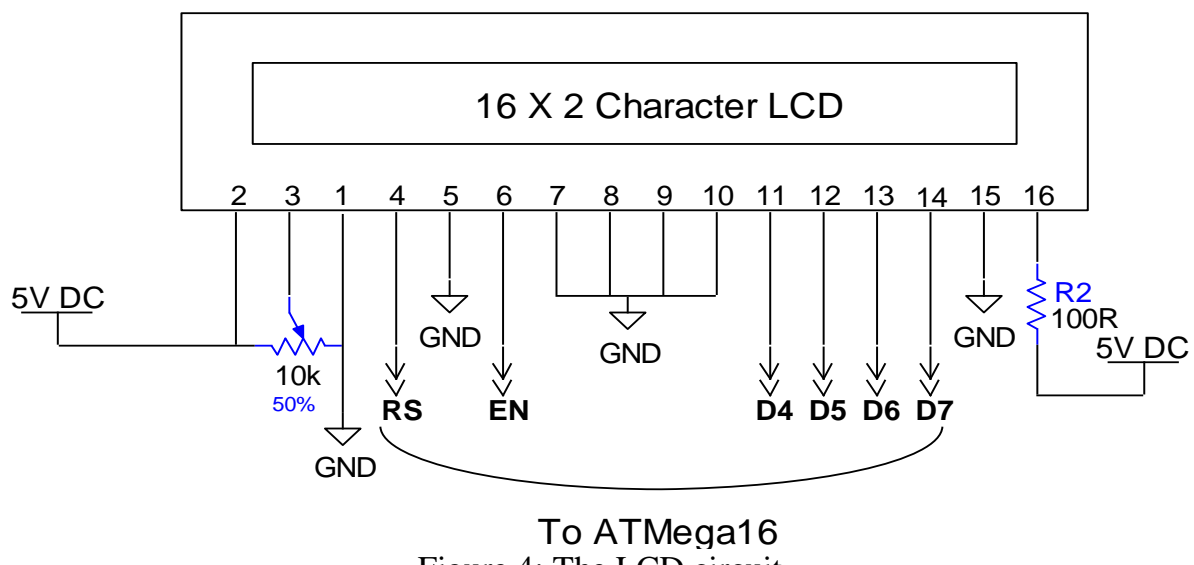

Figure 4: The LCD circuit

\section{ATmega 16 AVR circuit}

The heart of the system is the AVR microcontroller. It is a 40pin dip used to control the activities of all other sections. ATmega16 AVR was selected due to its good features of being cheap and readily available in the market it also has high performance low power consumption 8 bit operation with 130 powerful instructions. The symbol and pin connections is as shown in Figure 4

\begin{tabular}{|c|c|c|c|c|c|c|c|}
\hline & & & & & & & \\
\hline (XСК/TO) & PBO & 므 & 1 & 40 & $\sqsupseteq$ & PAO & $(A D C O)$ \\
\hline (T1) & PB1 & ㅁ & 2 & 39 & 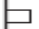 & PA1 & (ADC1) \\
\hline (INT2/AINO) & PB2 & 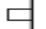 & 3 & 38 & 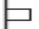 & PA2 & (ADC2) \\
\hline (OCO/AIN 1 ) & PB3 & 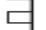 & 4 & 37 & $巨$ & PA3 & (ADC3) \\
\hline (SS) & PB4 & 口 & 5 & 36 & $\sqsupseteq$ & PA4 & (ADC4) \\
\hline (MOSI) & PB5 & ㅁ & 6 & 35 & $\sqsupseteq$ & PA5 & (ADC5) \\
\hline (MISO) & PB6 & ㅁ & 7 & 34 & $\sqsupseteq$ & PA6 & (ADC6) \\
\hline (SCK) & PB7 & 므 & 8 & 33 & $\sqsupseteq$ & PA7 & (ADC7) \\
\hline & ESET & ㅁ & 9 & 32 & $巨$ & AREF & \\
\hline & $V C C$ & 口 & 10 & 31 & 曰 & GND & \\
\hline & GND & 口 & 11 & 30 & 巨 & AVCO & \\
\hline & TAL2 & 口 & 12 & 29 & ص & $\mathrm{PC} 7$ & (TOSC2) \\
\hline & TAL1 & ㅁ & 13 & 28 & 巨 & PC6 & (TOSC1) \\
\hline$(R \times D)$ & PDO & ㅁ & 14 & 27 & 巨 & PC5 & (TDI) \\
\hline$(T \times D)$ & PD1 & ㅁ & 15 & 26 & 巨 & $\mathrm{PC} 4$ & (TDO) \\
\hline (INTO) & PD2 & 口 & 16 & 25 & 巨 & $\mathrm{PC}_{3}$ & (TMS) \\
\hline (INT1) & PD3 & ㅁ & 17 & 24 & 巨 & $\mathrm{PC} 2$ & (TCK) \\
\hline (OC1B) & PD4 & ㅁ & 18 & 23 & 巨 & $\mathrm{PC} 1$ & (SDA) \\
\hline (OC1A) & PD5 & ㅁ & 19 & 22 & 曰 & $\mathrm{PCO}$ & (SCL) \\
\hline (ICP1) & PD6 & ᄃ & 20 & 21 & 口 & PD7 & $(\mathrm{OC} 2)$ \\
\hline
\end{tabular}

Figure 5: ATmega16 symbol

Pins 12 and 13 serves as the crystal input and output of an inverting amplifier and it is configured as an On-chip oscillator. The connection as specified by the data sheet is as shown 


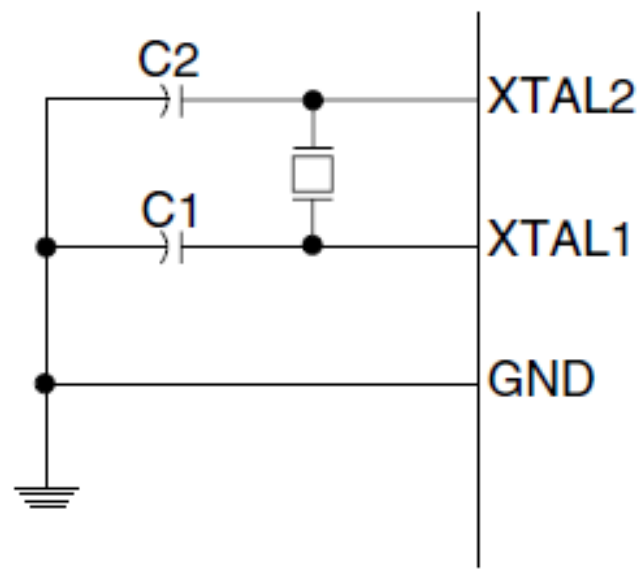

Figure 6: Microcontroller oscillator

It is recommended (ATmega16 data sheet) that the values of the capacitors be in such a manner that $\mathrm{C}_{1}=\mathrm{C}_{2}$

And that the value should be between 12 and $22 \mathrm{pF}$.

For these reasons we used 2 numbers of $22 \mathrm{pF}$ capacitors and a crystal of value $11.0592 \mathrm{MHz}$

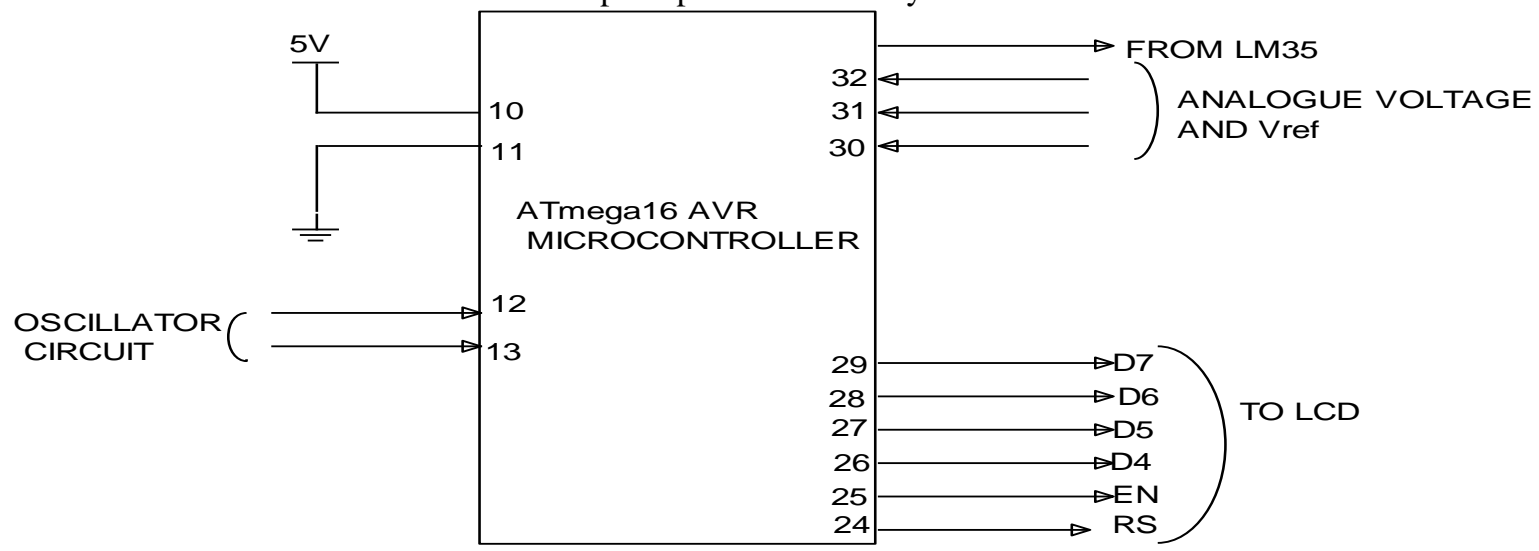

Figure 7: ATmega 16 circuit

The temperature condition at any instant as sensed by the LM35 is displayed on a Liquid Crystal Display (LCD). To do this the ATmega16 is programmed to copy the output of the ADC and convert the result to ASCII then transferred to the LCD to be displayed. The flow chart below shows the software algorithm of the AVR microcontroller.

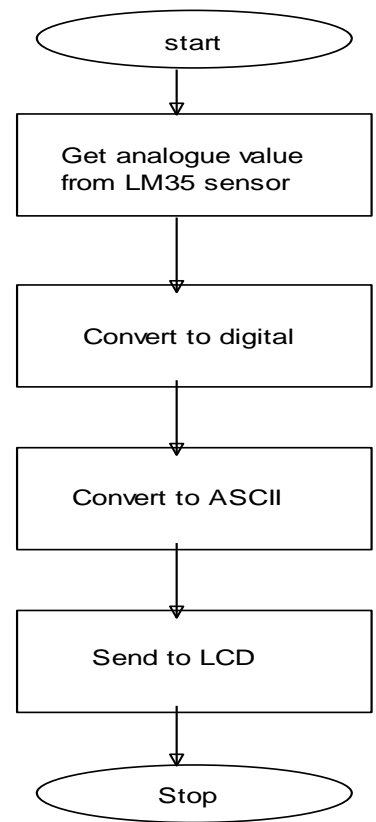

Figure 8: ATmega16 software flow chart 
LM35 circuit.

\section{Circuit Construction And Testing}

The LM35 temperature sensor circuit was constructed using the following components;

Table 1: LM35 list of components

\begin{tabular}{|l|l|l|l|}
\hline S/N & Component & Description & Quantity \\
\hline 1 & Temperature sensor & LM35 & 1 \\
\hline 2 & Capacitor & $1 \mathrm{uF}$ & 1 \\
\hline 3 & Resistor & $75 \mathrm{k}$ & 1 \\
\hline
\end{tabular}

The LM35 circuit was constructed with the capacitor connected very close to the IC. The wires were covered up with a tape which will ensure that the leads and wires are all at the same temperature at the surface, and that the LM35 die's temperature will not be affected by the air temperature to ensure accuracy. The wire was twisted together to reduce the length hence making it more convenient and beautiful. The constructed temperature sensor is shownas in plate 1

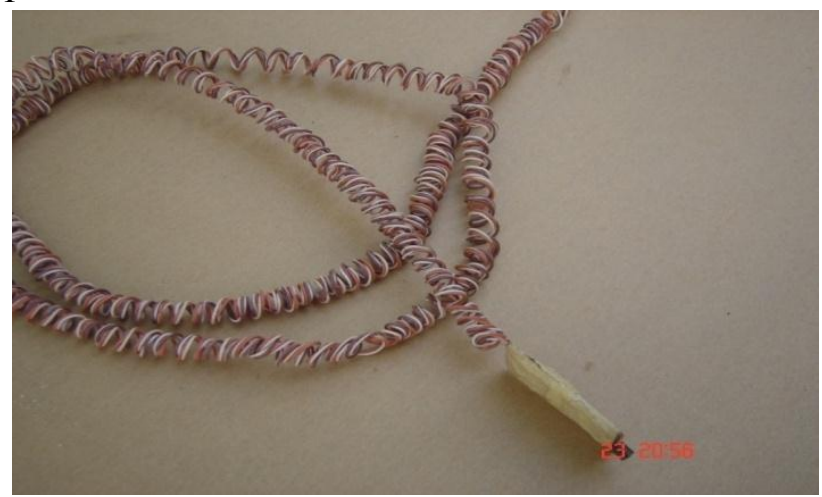

Plate 1: constructed sensor circuit

Table 2: ATmega16 module list of components

\begin{tabular}{|l|l|l|l|}
\hline $\mathbf{S} / \mathbf{N}$ & Components & Description & Quantity \\
\hline 1 & Resistors & $\mathbf{4 K} 7$ & 9 \\
\hline $\mathbf{2}$ & Capacitor & $\mathbf{2 2 u F}$ & $\mathbf{2}$ \\
\hline $\mathbf{3}$ & Capacitor & $100 \mathrm{nF}$ & $\mathbf{1}$ \\
\hline $\mathbf{4}$ & Crystal & $11.0592 \mathrm{MHZ}$ & $\mathbf{1}$ \\
\hline $\mathbf{5}$ & Microcontroller & ATmega 16 & \\
\hline $\mathbf{6}$ & Connector & 4 wire & $\mathbf{1}$ \\
\hline
\end{tabular}

The main microcontroller circuit was constructed on a board as shown in plate 2 .

A 40 pin socket was first soldered to the board then the IC was plugged in. This allows for easy maintainability as they could easily be replaced.

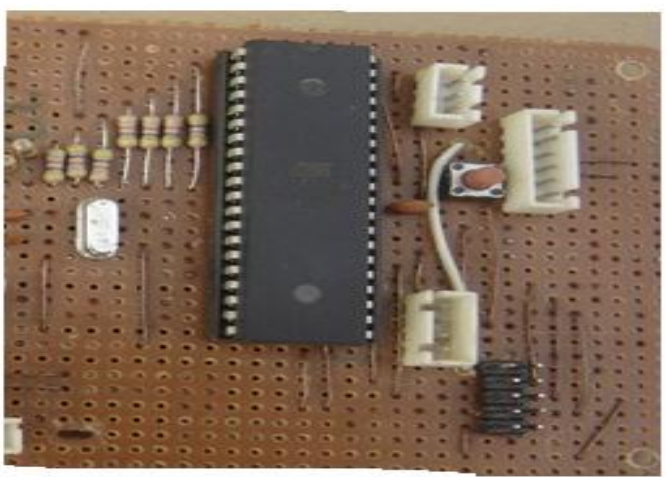

Main microcontroller circuit

Plate 2: ATmega16 module

\section{THE LCD CIRCUIT CONSTRUCTION}

The LCD display unit circuit was constructed on the circuit board using the components listed below. 


Table 3: LCD circuit list of components
\begin{tabular}{|l|l|l|l|}
\hline S/N & Components & Description & Quantity \\
\hline 1 & LCD & $16 \times 2$ & 1 \\
\hline 2 & Capacitor & $100 \Omega$ & 1 \\
\hline 3 & Resistor & $10 \mathrm{~K}$ & 1 \\
\hline
\end{tabular}

The constructed LCD circuit is shown in plate 3. The components were placed at the back of the board for casing purpose.

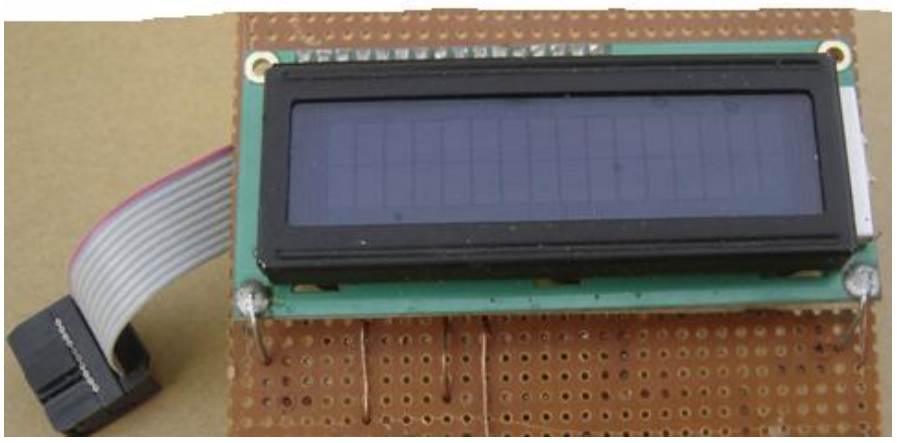

Plate 3: The LCD constructed module

\section{THERMOMETER TESTING}

To test the accuracy of the constructed thermometer a digital thermometer type (ST-9269 MULTISTEM THERMOMETER) was obtained and used to conduct an experiment to compare the temperature measurements of the two. The jug as shown in plate 4 was half filled with hot water and the two sensors were inserted through a hole and above the water to measure the temperature of the enclosure at random intervals.

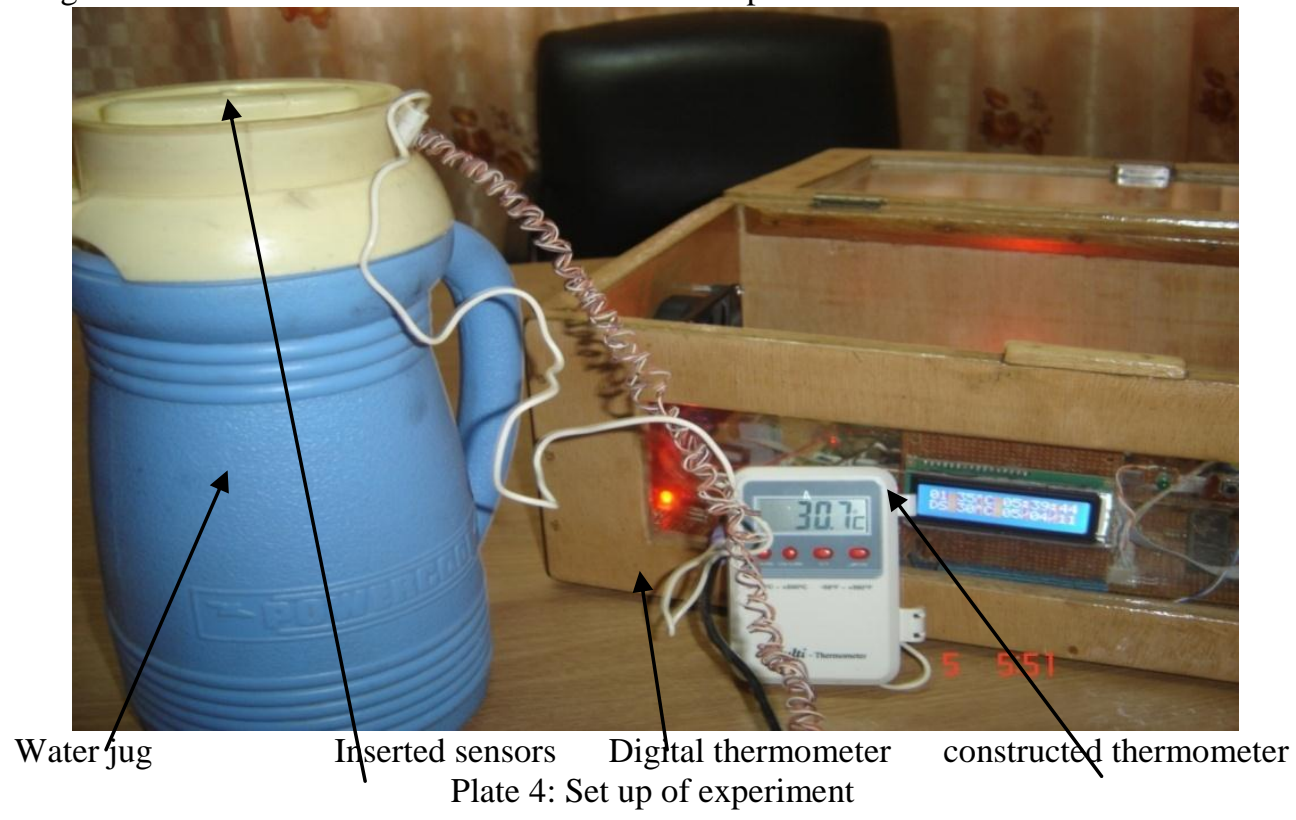

\section{Results}

The result of the experiment to compare the accuracy of the constructed thermometer is tabulated in table 1 Table 4: Temperature of the two thermometers

$\begin{array}{lcc}\text { System temp }\left({ }^{\circ} \mathrm{C}\right) & \text { Digital temp }\left({ }^{\circ} \mathrm{C}\right) & \text { difference } \\ 33 & 33.2 & 0.2 \\ 38 & 37.9 & 0.1 \\ 40 & 39.7 & 0.3 \\ 42 & 42.5 & 0.5 \\ 46 & 46.3 & 0.3 \\ 48 & 47.9 & 0.1 \\ 50 & 50.0 & 0.0 \\ 52 & 52.3 & 0.3 \\ 56 & 55.9 & 0.1 \\ 57 & 57.1 & 0.1\end{array}$




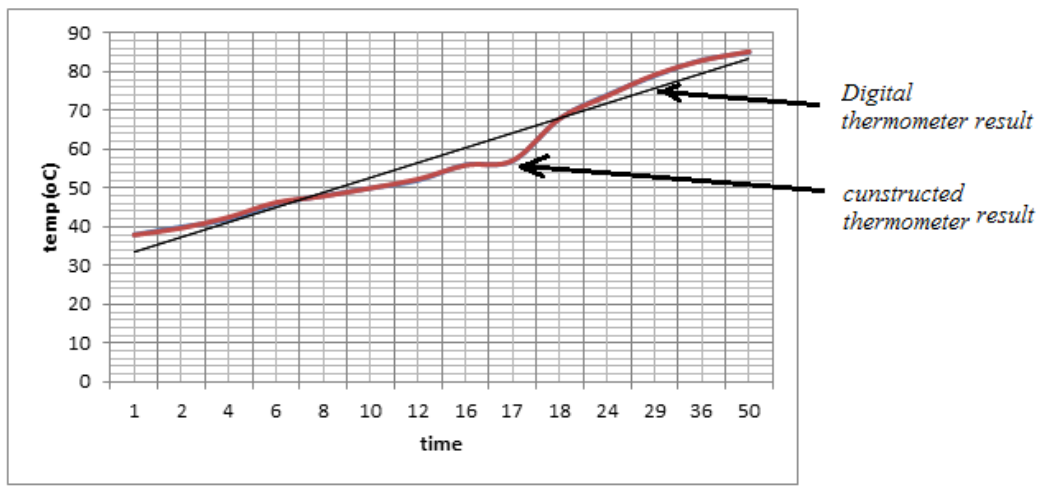

Figure 9: A plot of the measured temperatures against time.

\section{Discussion}

As could be seen from the table the difference ranges from 0.0 to 0.5 . The results obtained as tabulated show that there are small deviations between the two temperatures. The possible reason for the slight difference in the measured temperatures is that the resolution of the $\mathrm{ADC}$ is $1^{\circ} \mathrm{C}$. This means that temperatures are rounded up to the nearest whole number during $\mathrm{ADC}$ conversion process. The measured temperature is therefore likely to have error of 0 to $\pm 0.5{ }^{\circ} \mathrm{C}$ from the actual value. The percentage error is significant at low temperature and negligible at higher values.

\section{Conclusion}

In this manuscript, a digital thermometer has been designed using an AVR microcontroller as the heart of the system. To sense the temperature to be measured and LM35 sensor was employed. The measured temperature is then converted to digital format by an ADC located internally in the AVR microcontroller and displayed on an LCD.

It is suggested that this thermometer may be improved upon by using a more sensitive sensor to make it suitable for measurements at lower temperatures. A memory device may also be incorporated to store the measured results.

\section{References}

[1] ATmmega16 Data Book. (2001, November 4). Atmega16. Retrieved May 5, 2011, from ATmel corporation: http;/www.atmel.com

[2] Bellis, M. (2011). The history of thermometer. Retrieved November 4, 2011, from The New York Times Company: About.com.Inventors

[3] Halden, A. V. (1995). The Thermometer. Retrieved January 15, 2011, from The Galileo Project.

[4] LM35 Data Book. (2000, 11). LM35 Presition Centigrade Temperature Sensors. Retrieved May 5th, 2010, from National Semiconductor corporation: http;//www.national.com

[5] LM7805Databook. (2001). KA78XX/KA78XXA 3-Terminal1A positive voltage regulator. Retrieved SEPTEMBER 6, 2009, from Fairchild Semicondoctor Corporation: http;//www.fairchildsemi.com

[6] Sigurssen, A. (2003, October 5). History of the thermometer. Retrieved Nuvember 28, 2011, from Newsfinder: Newsfinder.org

[7] Wikkipedia. (2011, September 18). Thermometer. Retrieved December 7, 2011, from Wikkipedia the free encyclopedia. 